\title{
Helicobacter pylori and early gastric cancer
}

\author{
M E Craanen, P Blok, W Dekker, G N J Tytgat
}

\begin{abstract}
The relation between Helicobacter pylori, intestinal metaplasia, and early gastric cancer was studied by examining gastrectomy specimens from 31 intestinal type and 22 diffuse type carcinomas. $A$ total of 298 patients with antral gastritis were used as controls. Atrophic changes and intestinal metaplasia were significantly more common in intestinal type early gastric cancer compared with diffuse type early gastric cancer $(\mathbf{p}<0.05$ and $\mathbf{p}<0.001$, respectively). $H$ pylori was found in $61.3 \%$ of intestinal type early gastric cancer and in $54.5 \%$ of diffuse type early gastric cancer (NS). The age adjusted prevalence of intestinal metaplasia in the patients with antral gastritis was higher in $H$ pylori positive patients in all age groups studied. Comparing gastritis patients with patients with intestinal type early gastric cancer showed the age adjusted prevalence of intestinal metaplasia to be significantly higher in the patients with early gastric cancer in all age groups studied. In conclusion, $H$ pylori is associated with both types of early gastric carcinoma. Intestinal metaplasia formation seems to be a multifactorial process in which $H$ pylori may play a part. These findings suggest that gastric cancer may be included in the spectrum of $H$ pylori associated diseases, although many questions about causality remain to be answered.
\end{abstract}

(Gut 1994; 35: 1372-1374)

Several follow up studies on gastritis suggest a slow and gradual progression of chronic active gastritis to chronic gastritis with variable degree of atrophy and intestinal metaplasia. ${ }^{1-4}$ Chronic atrophic gastritis and intestinal metaplasia are widely recognised as being the most prevalent of all conditions associated with an increased gastric cancer risk. ${ }^{56}$ In view of these data and in recognition of the important role of Helicobacter pylori (H pylori) in the gastric inflammatory process, it is not surprising that its potential role in the development of premalignant and maligant changes in the stomach is a subject of interest. Several histological studies have reported on the association between $H$ pylori and gastric carcinoma using mainly gastrectomy specimens from advanced cancers $^{7-9}$ We feel that studying the mucosal characteristics of stomachs harbouring early gastric carcinoma is more suitable for studying the association between $H$ pylori and tumour histology. This is based on the assumption that the mucosa of such stomachs is more preserved than the mucosa of stomachs harbouring advanced cancers. This study, therefore, reports the prevalence of $H$ pylori in both types of gastric carcinoma using gastrectomy specimens from early cancers. The possible role of $H$ pylori in the development of intestinal metaplasia is further explored by comparing age grouped data from patients with antral gastritis and both types of early gastric cancer.

\section{Methods}

For the purpose of this study, all gastrectomy specimens of early gastric carcinomas diagnosed in the period 1973 to 1990 were retrieved from the files of the pathology department (Public Health Laboratory Haarlem). The gastrectomy specimens were opened along the greater curvature and pinned out on to a cork mat. After fixation in $10 \%$ buffered formalin, multiple blocks were taken from the tumour, its surrounding mucosa, antrum, and body (proximal resection margin in most cases). A section was also taken from the lesser curvature. All samples were embedded in paraffin wax, cut at $5 \mu$ and stained with haematoxylin and eosin for diagnosis. Early gastric cancer was defined as carcinoma confined to the mucosa or submucosa with or without lymph node metastasis according to the Japanese Gastrointestinal Endoscopy Society. ${ }^{10} \mathrm{~A}$ total of 53 cases was identified. The tumour site was noted and the tumour type according to Lauren ${ }^{11}$ was reassessed independently by two of the authors (MC/PB). Discrepancies in findings, although rare, were discussed until agreement was reached. All tissue blocks of non-malignant antral mucosa were recut and stained by haematoxylin and eosin and Giemsa. The presence of $H$ pylori, the type of gastritis, and the presence and extent of intestinal metaplasia were assessed according to the Sydney system. ${ }^{12}{ }^{13}$ From our previously reported prospective endoscopicbioptic study, ${ }^{14}$ subjects with a histological diagnosis of antral gastritis $(n=298)$ were used as controls. This group of patients was stratified according to age and the presence of intestinal metaplasia and $H$ pylori

TABLE I Grades of $\mathrm{H}$ pylori density in early gastric carcinoma according to the Sydney classification

\begin{tabular}{lll}
\hline Density & I-EGC $(\mathrm{n}=31)(\%)$ & D-EGC $(\mathrm{n}=22)$ \\
\hline 0 & $12(38 \cdot 7)$ & $10(45 \cdot 5)$ \\
1 & $7(22 \cdot 6)$ & $8(36 \cdot 4)$ \\
2 & $12(38 \cdot 7)$ & $4(18 \cdot 1)$ \\
3 & $0(0)$ & $0(0)$ \\
\hline
\end{tabular}

0: $H$ pylori absent, 1 ; individual organisms or small groups covering less than one third of the mucosal surface, 2; between 1 and 3, 3; the presence of large groups of organisms on the surface and upper pits of more than two third of mucosal surface examined. I-EGC=intestinal type early gastric cancer, $\mathrm{D}-\mathrm{EGC}=$ diffuse type early gastric cancer. 
TABLE II Prevalence of $\mathrm{H}$ pylori according to age group and histological tumour type

\begin{tabular}{lccclc}
\hline Age $(y)$ & Number & $H P+(\%)$ & I-EGC: $D-E G C$ & $\begin{array}{l}\% I-E G C \\
H P+(n)\end{array}$ & $\begin{array}{c}\% D-E G C \\
H P 2(n)\end{array}$ \\
\hline $30-39$ & 1 & $0(0)$ & $0: 1$ & NA & NA \\
$40-49$ & 5 & $2(40)$ & $1: 4$ & NA & $50(2)$ \\
$50-59$ & 16 & $11(68 \cdot 8)$ & $5: 11$ & $60(5)$ & $54 \cdot 5(6)$ \\
$60-69$ & 13 & $8(61 \cdot 5)$ & $10: 3$ & $60(6)$ & $66 \cdot 6(2)$ \\
$70-79$ & 10 & $6(60)$ & $8: 2$ & $50(4)$ & $100(2)$ \\
$\geqslant 80$ & 8 & $4(50)$ & $7: 1$ & $67(4)$ & $0(0)$ \\
Total & 53 & $31(58 \cdot 5)$ & $31: 22$ & $61 \cdot 3(19)$ & $54 \cdot 5(12)$ \\
\hline
\end{tabular}

$\mathrm{HP}=H$ pylori, $\mathrm{I}-\mathrm{EGC}=$ intestinal type early gastric carcinoma, $\mathrm{D}-\mathrm{EGC}=$ diffuse type early gastric carcinoma, NA = not applicable.

were reassessed independently by two of the authors (MC/PB). Finally, age grouped data of patients with antral gastritis were compared with similar data of patients with both types of early gastric cancer for the prevalence of $H$ pylori and intestinal metaplasia.

\section{STATISTICS}

The $\chi^{2}$ test and the two tailed Student's $t$ test were used to analyse the data, when appropriate.

\section{Results}

EARLY GASTRIC CANCER PATIENTS

Thirty seven early gastric cancers were found in the antrum, 13 in the body, and three in the cardia/fundic region. There were 31 intestinal type early gastric cancers (median age 69) and 22 diffuse type early gastric cancer (median age 58.5). Atrophic mucosal changes were present in $90.3 \%$ (28 of 31 ) of intestinal type early gastric cancer and in 63.6\% (14 of 22) of diffuse type early gastric cancer $(p<0 \cdot 05)$. No significant difference in grade of atrophy was detected. Intestinal metaplasia was found in the mucosa surrounding intestinal type early gastric cancer and diffuse type early gastric cancer in $96.8 \%$ and $45.5 \%$ of the cases, respectively $(p<0.001)$. Moderate to severe intestinal metaplasia was only found in cases of intestinal type early gastric cancer $(p<0.001)$. $H$ pylori was found in the non-malignant antral mucosa of $61.3 \%$ (19 of 31) of intestinal type and in $54.5 \%$ (12 of 22 ) of diffuse type early gastric cancer (NS). No significant difference in bacterial load was found between both types (Table 1). When stratified according to age group, no significant difference in prevalence of $H$ pylori was found either between intestinal and diffuse type tumours (Table II).

TABLE III Prevalence of intestinal metaplasia per age group according to $\mathrm{H}$ pylori status in gastritis patients

\begin{tabular}{llllll}
\hline Age $(y)$ & Number & $H P+(n)$ & $I M+(\%)$ & $H P-(n)$ & $I M+(\%)$ \\
\hline $20-29$ & 16 & 10 & 10 & 6 & 0 \\
$30-39$ & 26 & 23 & 23 & 3 & 0 \\
$40-49$ & 45 & 34 & $20 \cdot 6$ & 11 & $9 \cdot 1$ \\
$50-59$ & 61 & 57 & $31 \cdot 8$ & 4 & 25 \\
$60-69$ & 60 & 49 & $36 \cdot 7$ & 11 & $18 \cdot 2$ \\
$70-79$ & 56 & 43 & $51 \cdot 2$ & 13 & $23 \cdot 1$ \\
$\geqslant 80$ & 34 & 12 & $58 \cdot 3$ & 22 & $22 \cdot 7$ \\
Total & 298 & 228 & $33 \cdot 3^{\star}$ & 70 & $17 \cdot 4$ \\
\hline
\end{tabular}

${ }^{\star} \mathrm{p}<0 \cdot 02, \mathrm{HP}=H$ pylori, $\mathrm{IM}=$ intestinal metaplasia.

\section{GASTRITIS PATIENTS}

There were 298 patients with histological diagnosis of antral gastritis. A total of 1082 antral biopsy specimens were examined (mean (SEM) $3.6(2.8)$ per patient). $H$ pylori was found in 228 patients $(76.5 \%)$. Intestinal metaplasia was found in 88 patients $(29.5 \%)$. Its prevalence increased with age. The prevalence of intestinal metaplasia was higher in the $H$ pylori positive group than in the $H$ pylori negative group $(33.3 \%$ v $17 \cdot 4 \%$, $\mathrm{p}<0.02)$. The extent of intestinal metaplasia in the last two groups was not significantly different. In each age group the prevalence of intestinal metaplasia was higher in the $H$ pylori positive patients than in the $H$ pylori negative patients, although these differences did not reach statistical significance (Table III).

\section{COMPARISON BETWEEN GASTRITIS AND EARLY} GASTRIC CANCER PATIENTS

Age adjusted comparison between patients with intestinal type early gastric cancer and gastritis patients showed the antral prevalence of intestinal metaplasia to be significantly higher in early gastric cancer patients (Table IV). No significant difference in prevalence of $H$ pylori was found. Comparison between gastritis patients and patients with diffuse type early gastric cancer showed no significant difference in prevalence of $H$ pylori and intestinal metaplasia.

\section{Discussion}

At present, conflicting data from various histological studies on the association between $H$ pylori and both Lauren types of gastric carcinoma can be found in published reports. One retrospective histological study reported a strong association between $H$ pylori infection and intestinal type but not diffuse type gastric carcinoma. ${ }^{7}$ Other investigators, however, did not find a significant difference in association between $H$ pylori and both types of gastric carcinoma. ${ }^{89}$ The last three histological studies only focused on the mucosal background of advanced cancers. In our study, using only early gastric cancers, $H$ pylori associated gastritis was the mucosal background lesion in most diffuse type early cancers as well. No significant difference in the prevalence of $H$ pylori between both types of early gastric cancer was found. A confounding factor might be the gastric mucosa becoming increasingly inhospitable for $H$ pylori in the process of progressive atrophy and intestinal metaplasia formation. The higher prevalence of atrophy and intestinal metaplasia in intestinal type early gastric cancer in our study may have led to the disappearance of the micro-organism resulting in a lower observed than expected prevalence of $H$ pylori in cases of intestinal type early gastric cancer. Nevertheless, in view of the generally accepted pathogenesis of both types of gastric cancer, ${ }^{15-17}$ it might have been expected that there would be a strong association between $H$ pylori and intestinal type tumours only. Our study 
TABLE IV Age related comparison of the prevalence of $\mathrm{H}$ pylori and intestinal metaplasia in patients with antral gastritis $(n=298)$ and early gastric carcinoma $(n=53)$

\begin{tabular}{lllllll}
\hline Age (y) & $\begin{array}{l}\text { Gastritis } \\
H P+(\%)\end{array}$ & $I M+(\%)$ & $\begin{array}{l}I-E G C \\
H P+(\%)\end{array}$ & $I M+(\%)$ & $\begin{array}{l}D-E G C \\
H P+(\%)\end{array}$ & $I M+(\%)$ \\
\hline $20-29$ & $62 \cdot 5$ & $6 \cdot 25$ & NA & NA & NA & NA \\
$30-39$ & $88 \cdot 4$ & 11.5 & NA & NA & NA & NA \\
$40-49$ & $75 \cdot 6$ & $17 \cdot 8$ & NA & NA & 50 & 25 \\
$50-59$ & $93 \cdot 4$ & 31.1 & 100 & $100^{\star}$ & $54 \cdot 5$ & $54 \cdot 5$ \\
$60-69$ & $80 \cdot 3$ & 33.3 & 60 & $100+$ & 66.6 & 66.6 \\
$70-79$ & 76.8 & 44.6 & 50 & $100 \ddagger$ & 100 & 50 \\
$\geqslant 80$ & $35 \cdot 3$ & 35.3 & $57 \cdot 1$ & 1005 & NA & NA \\
\hline
\end{tabular}

IM; gastritis $v$, intestinal type early gastric carcinoma, ${ }^{\star} \mathrm{p}<0.01, \mathrm{fp}<0.001, \neq \mathrm{p}<0.05, \oint \mathrm{p}<0.01$. Abbreviations as in Table II. one or both types of gastric cancer or changes the natural history of $H$ pylori induced mucosal injury, or both.

1 Ihamäki T, Kekki M, Sipponen P, Siurala M. The sequelae and course of chronic gastritis during a 30-34 year bioptic follow-up study. Scand $\mathcal{F}$ Gastroenterol 1985; 20: 485-91.

2 Villako K, Kekki M, Tamm A, Tammur R, Savisaar E, Viirsalu V, et al. Epidemiology and dynamics of gastritis in a representative sample of Estonian urban population. Scand f Gastroenterol 1982; 17: 601-7.

3 Villako K, Kekki M, Maaroos H-I, Sponnen P, Uibo R, Tammur $\mathbf{R}$, et al. Chronic gastritis: progression of inflammation and atrophy in a six year endoscopic follow-up of a random sample of 142 Estonian urban subjects. $S$ cand $f$ Gastroenterol 1991; 26 (suppl 186): 135-41.

4 Kekki M, Siurala M, Varis K, Sipponen P, Sistonen P, Nevanlinna RH. Classification principles and genetics of chronic gastritis. Scand $\mathcal{f}$ Gastroenterol 1987; 22: (suppl chronic gastrit

clearly shows, however, a strong association between $H$ pylori and diffuse type tumours as well. Our finding is in agreement with several serological studies reporting on the association between $H$ pylori and gastric carcinoma. ${ }^{18} 19$ Sipponen et al postulate that the morphogenesis of gastric cancer may depend on the stage of the $H$ pylori related gastritis. Chronic inflammation may particularly promote the morphogenesis of diffuse type carcinoma, whereas the atrophic and metaplastic changes promote and favour the morphogenesis of intestinal type carcinoma. ${ }^{20}$ Recent data on HLA-DR antigen expression in gastritis and gastric carcinoma, however, do not support Sipponen's view, but rather suggest that both types of gastric cancer constitute two distinct subtypes, only the intestinal type arising from the HLA-DR positive epithelial of chronic gastritis. 2122

The risk of gastric carcinoma attributable to $H$ pylori has been estimated at roughly $60 \%$. $^{18} 19$ To establish a better understanding of how $H$ pylori might participate in gastric cancer development, it is important to elucidate its role in the preneoplastic process leading to gastric carcinoma. Intestinal metaplasia, generally considered a marker of premalignant change leading to gastric cancer of the intestinal type, was found more often in gastritis patients in all age groups studied in case they were $H$ pylori positive. Other reports show similar results. ${ }^{23} 24$ This suggests that $H$ pylori is indeed a factor in intestinal metaplasia development, possibly by inducing a hyperproliferative state in the inflamed mucosa. 2526 Moreover, the age adjusted prevalence of intestinal metaplasia was higher in patients with intestinal type early gastric cancer than in patients with gastritis. As $H$ pylori induced gastritis was the background lesion in most of the intestinal type cancers, it is suggested that gastritis and intestinal metaplasia progress more rapidly in patients prone to intestinal type tumours than in patients with gastritis. Sipponen et al reported similar data. ${ }^{27} 28$ This rapid progression probably results from a multifactorial process, in which environmental, dietary, and genetic factors all play a part.

In conclusion, it is suggested that $H$ pylori induced gastritis may evolve into intestinal metaplasia. It seems that $H$ pylori relates to both types of gastric cancer, in what is in all probability a dynamic multifactorial process. It is therefore mandatory to devise a programme to prevent or to cure the infection and then to find out if this intervention reduces the risk of
Correa P. Precursors of gastric and esophageal cancer. Cancer 1982; 50: 2554-65.

6 Sipponen P, Kekki M, Haapakoski J, Ihamäki T, Siurala M. Gastric cancer risk in chronic atrophic gastritis: statistical calculations of cross sectional data. Int $\mathcal{f}$ Cancer 1985; 35: 173-7.

7 Parsonnet J, Vandersteen DP, Goates J, Sibley RK, Pritikin J, Chang Y. Helicobacter pylori in intestinal- and diffusetype gastric adenocarcinomas. $\mathcal{F}$ Natl Cancer Inst 1991; 83: 640-3.

8 Loffeld RJLF, Willems I, Flendrig JA, Arends JW. Helicobacter pylori and gastric carcinoma. Histopathology 1990; 17: 537-41.

9 Wee A, Kang JY, Teh M. Helicobacter pylori and gastric cancer: correlation with gastritis, intestinal metaplasia, and tumour histology. Gut 1992; 33: 1029-32.

10 Murakami T. Pathomorphological diagnosis. Definition and gross classification of early gastric cancer. In Murakami T, ed. Early gastric cancer. Gann monograph on cancer research. Tokyo: University of Tokyo Press, 1971; 11: 53-5.

11 Lauren P. The two histological main types of gastric carcinoma: diffuse and so-called intestinal-type carcinoma. Acta Pathol Microbiol Scand 1965; 64: 31-49.

12 Misiewicz J. The Sydney system: a new classification of gastritis. Introduction. f Gastroenterol Hepatol 1991; 6: gastritis.

13 Price AB. The Sydney system: histological division. $f$ Gastroenterol Hepatol 1991; 6: 209-22.

14 Craanen ME, Dekker W, Blok P, Ferwerda J, Tytgat GNJ scopic-bioptic study of the gastric antrum. Gut 1992; 33: $16-20$

15 Correa P. A human model of gastric carcinogenesis. Cancer Res 1988; 48: 1319-26.

16 Taki K, Kuwabara N. Studies on histogenesis of the gastric carcinoma using minute cancers. Pathol Res Pract 1981, 72: 176-90.

17 Hirota $T$, Itabashi $M$, Suzuki $K$, Yoshida S. Clinicopathologic study of minute and small early gastric cancer. Pathol Annu 1980; 15: 1-19.

18 Nomura A, Stemmermann GN, Chyou P-H, Kato I, PerezPerez GI, Blaser MJ. Helicobacter pylori infection and Perez GI, Blaser MJ. Helicobacter pylori infection and gastric carcinoma among Japanese

19 Parsonnet J, Friedman GD, Vandersteen DP, Chang Y, Vogelman JH, Orentreich $\mathrm{N}$, et al. Helicobacter pylori 1991; 325: 1127-31

20 Sipponen P, Kosunen TU, Valle J, Riihela M, Seppala K, Helicobacter pylori infection and chronic gastritis in gastric cancer. $f$ Clin Pathol 1992; 45: 319-23.

21 Wee A, Teh M, Kang JY. Association of Helicobacter pylor with HLA-DR antigen expression in gastritis. $\mathcal{F}$ Clin Pathol 1992; 45: 30-3.

22 Teh M, Lee Y-S. HLA-DR antigen expression in intestinaltype and diffuse type gastric carcinoma. Cancer 1992; 69: type and

23 Rugge $M$, Mario di F, Cassaro M, Baffa $R$, Farinati F, Rublo J, et al. Pathology of the gastric antrum and body associated with Helicobacter pylori infection in non-ulcermetaplasia ? Histopathology 1993; 22: 9-15.

24 Guarner J, Mohar A, Parsonnet J, Halperin D. The association of Helicobacter pylori with gastric cancer and preneoplastic lesions in Chiapas, Mexico. Cancer 1993; 71: 297-301.

25 Scott N, Lansdown M, Diament R, Rathbone B, Murday V, Wyatt JI, et al. Helicobacter gastritis and intestinal metaplasia in a gastric cancer family. [Letter]. Lancet 1990, 335: 728 .

26 Correa P, Ruiz B. Campylobacter pylori and gastric cancer. In: Rathbone BJ, Heatley RV, eds. Campylobacter pylori and gastroduodenal disease. Oxford: Blackwell Scientific, 1989: 139-45.

27 Sipponen $P$, Kekki $M$, Siurala $M$. Atrophic gastritis and intestinal metaplasia in gastric carcinoma. Comparison intestinal metaplasia in gastric carcinoma. Comparison with a repre.

28 Sipponen $P$, Kekki M, Siurala M. Age-related trends of gastritis and intestinal metaplasia in gastric carcinoma patients and in controls representing the population at large. $B r \mathcal{F}$ Cancer 1984; 49: 521-30. Intestinal metaplasia and Helicobacter pylori: an endoinfection and the risk of gastric carcinoma. $N$ Engl $\mathcal{F} \mathrm{Med}$ ous patients: is the bacterium a promoter of intestinal 